\title{
Optical coherence tomography of the pancreatic and bile ducts: are we ready for prime time?
}

\section{(ㄷ)(구) $\odot$}

Authors

Amy Tyberg ${ }^{1}$, Isaac Raijman ${ }^{6}$, Aleksey A. Novikov', Divyesh V. Sejpal ${ }^{4}$, Petros C. Benias ${ }^{4}$, Arvind J. Trindade ${ }^{4}$, Ananya Das $^{5}$, Mankanwal Sachdev ${ }^{5}$, Farhoud Khosravi ${ }^{5}$, Paul Tarnasky ${ }^{3}$, Prashant Kedia ${ }^{3}$, Monica Gaidhane ${ }^{1}$, Michel Kahaleh ${ }^{1}$, Virendra Joshi

\section{Institutions}

1 Robert Wood Johnson Medical School, Rutgers University, New Brunswick, New Jersey, United States

2 Ochsner, New Orleans, Louisiana, United States

3 Methodist Hospital, Dallas, Texas, United States

4 Northshore University Hospital, Manhasset, New York, United States

5 Arizona Center for Digestive Health, Phoenix, Arizona, United States

6 Greater Houston Gastroenterology, Houston, Texas, United States

submitted 29.6.2019

accepted after revision 9.12.2019

\author{
Bibliography \\ DOI https://doi.org/10.1055/a-1119-6248 | \\ Endoscopy International Open 2020; 08: E644-E649 \\ (c) Georg Thieme Verlag KG Stuttgart · New York \\ eISSN 2196-9736
}

Corresponding author

Michel Kahaleh, MD, AGAF, FACG, FASGE, Professor of Medicine, Clinical Director of Gastroenterology, Chief of Endoscopy, Director Pancreas Program, Department of Medicine I Rutgers Robert Wood Johnson Medical School, Rutgers, The State University of New Jersey, Robert Wood Johnson University Hospital, 1 RWJ Place, MEB 464, New Brunswick, NJ 08901

Fax: +1-732-235-5537

mkahaleh@gmail.com

\section{ABSTRACT}

Background and study aims First-generation optical coherence tomography (OCT) has been shown to increase diagnostic sensitivity for malignant biliary and pancreaticduct strictures. A newer OCT imaging system, NVision Volumetric Laser Endomicroscopy (VLE), allows for in vivo cross-sectional imaging of the ductal wall at the microstructure level during endoscopic retrograde cholangiopancreatography (ERCP). The aim of this study was to identify and evaluate characteristics on OCT that are predictive of benign and malignant strictures.

Patients and methods Consecutive patients from six centers who underwent OCT between September 2016 and September 2017 were included in a dedicated registry. OCT images were analyzed, and nine recurring characteristics were further assessed. Final diagnosis was based on histology and/or surgical pathology.

Results 86 patients were included (49\% male, mean age 64.7). OCT was performed in the bile duct in 79 patients and the pancreatic duct in seven. Nine OCT characteristics were identified: dilated hypo-reflective structures $(n=7)$, onion-skin layering $(n=8)$, intact layering $(n=17)$, layering effacement $(n=25)$, scalloping $(n=20)$, thickened epithelium $(n=42)$, hyper-glandular mucosa $(n=13)$, prominent blood vessels $(n=6)$, and a hyper-reflective surface $(n=$ 20). Presence of hyper-glandular mucosa, hyper-reflective surface and scalloping significantly increased the odds of malignancy diagnosis by 6 times more $(P=0.0203 ; 95 \% \mathrm{Cl}$ 1.3 to 26.5$), 4.7$ times more $(P=0.0255 ; 95 \% \mathrm{Cl} 1.2$ to $18.0)$ and 7.9 times more $(P=0.0035 ; 95 \% \mathrm{Cl} 1.97$ to 31.8$)$ respectively.

Conclusion By providing in-vivo cross-sectional imaging of the pancreatic and biliary duct wall, OCT technology may improve sensitivity in diagnosing malignant strictures and provide standardizable criteria predictive of malignancy. 


\section{Introduction}

Indeterminate biliary and pancreatic duct strictures remain a diagnostic challenge. Current diagnostic modalities including cytology brushing and confocal endomicroscopy are specific but inadequately sensitive [1]. Cholangioscopy provides additional benefit through direct visualization of pancreaticobiliary mucosa and targeted biopsies but is limited by the ability to visualize only the surface epithelium [2]. Optical coherence tomography (OCT) is a technology that uses infrared light to obtain high-resolution, cross-sectional tomographic imaging of tissue microstructure below the surface that can be interpreted in-vivo. Early versions of this technology showed successful delineation of mucosal layers and tissue microstructures; however, widespread adaptation was limited by shallow penetration depths and suboptimal resolution [3-11]. A newer version of this technology, NVision Volumetric Laser Endomicroscopy (VLE) (Ninepoint; Bedford, MA), allows for a wider and deeper field of vision and higher quality images. Small initial studies show feasibility and safety of this new technology and encouraging specificity of standardizable characteristics predictive of malignant and benign disease [12-14] aim of this study is to identify and evaluate characteristics on NVision VLE OCT that are predictive of benign and malignant pancreaticobiliary strictures.

\section{Patients and methods}

Consecutive patients from six tertiary centers who underwent OCT analysis of the pancreatic or biliary duct using NVision VLE technology between September 2016 and September 2017 were captured in a dedicated registry as part of a prospective observational study. Patient demographics, procedural information, post-procedure follow-up data, and adverse events were collected. Technical success was defined as successful completion of OCT evaluation performed at the time of ERCP.

\section{Technology}

OCT imaging was obtained using the NVision Volumetric Laser Endomicroscopy (VLE) Imaging System (NinePoint). This technology uses low-intensity infrared light at a wavelength ranging from 750 to 1300 to obtain high-resolution, cross-sectional imaging of tissue microstructure. [15]. The infrared light is directed into the tissue and to a reference mirror, and the light is scattered or reflected depending on tissue characteristics. Reflected photons are received by the detector and the depth is determined using interferometry [4]. Images are constructed by performing multiple axial measurements of backscattered light at different transverse positions with an axial and lateral resolution of 7 microns and 40 microns, respectively, and a depth of penetration of $3 \mathrm{~mm}$. The system uses a dedicated probe that is 7 French in diameter and can be advanced through the working channel of a standard duodenoscope. The probe is advanced to the area of interest and a 90 second scan encompassing a length of $6 \mathrm{~cm}$ is performed. Images are created in real time for in-vivo interpretation.

\section{Procedural technique}

The NVision VLE catheter with a dedicated probe was advanced through the working channel of the duodenoscope into the bile duct or pancreatic duct adjacent to the wire to the area of interest under fluoroscopic visualization. Removal of the wire prior to scanning was done at the discretion of the individual endoscopist. Once positioned, the 90 -second scan was performed, and the images were captured and interpreted in-vivo. In necessary cases, sequential scans were performed to capture the entire area of interest. The catheter was then removed. If prior stents had been placed, they were removed prior to catheter insertion. At the discretion of the endoscopist, cholangioscopy with biopsies and/or brushing for cytology was performed after OCT. A biliary or pancreatic stent was then placed for decompression as needed.

\section{Image interpretation}

OCT images were analyzed in vivo by each endoscopist and the findings were collected in a centralized database. Based on data from older-generation OCT studies as well as on recurring characteristics described by individual operators, nine specific characteristics were identified: dilated hypo-reflective structures, onion-skin layering, intact layering, layering effacement, scalloping, thickened epithelium, hyper-glandular mucosa, prominent blood vessels, and a hyper-reflective surface. Each of these characteristics were analyzed to be predictive of malignancy or benign disease. Final diagnosis was based on endoscopic histology and/or endoscopic or surgical pathology.

\section{Statistical analysis}

Logistic regression analysis was conducted for malignancy diagnosis predictors.

The stepwise multivariate analysis was conducted using model selection; using one level for features, and only predictors with $P<0.10$ were included in the model. All descriptive and statistical analyses were conducted using MedCalc V18.9 (MedCalc Software, Ostend, Belgium).

\section{Results}

Eight-six patients were included (49\% male, mean age 64.7) ( $\triangleright$ Table 1). The indication for ERCP was indeterminate biliary stricture $(n=38,44 \%)$, obstructive jaundice $(n=12,14 \%)$, abnormal imaging $(n=12,14 \%)$, abnormal liver tests $(n=12$, $14 \%)$, recurrent pancreatitis $(n=6,7 \%)$, indeterminate pancreatic duct stricture $(n=3,3 \%)$, pancreatic duct stone $(n=1)$, abnormal EUS $(n=1)$, ampullary adenoma $(n=1) .44$ patients (51\%) had a stent placed prior to OCT.

\section{Procedural data}

Technical success was achieved in all 86 patients (100\%). OCT was performed in the bile duct in 79 patients and the pancreatic duct in seven patients. Image quality was adequate for interpretation in all cases. Cholangioscopy or pancreatoscopy was concurrently performed in 47 (55\%) patients; confocal endomicroscopy was concurrently performed in two patients (2\%). 
- Table 1 Patient and procedure characteristics.

\begin{tabular}{|c|c|}
\hline & $n=86$ \\
\hline Age (mean) & 64.7 (STD 15.8) \\
\hline Gende - male & $42(49 \%)$ \\
\hline \multicolumn{2}{|l|}{ Indication for ERCP } \\
\hline - Indeterminate biliary stricture & 38 \\
\hline - Obstructive jaundice & 12 \\
\hline - Abnormal imaging & 12 \\
\hline - Pancreatitis & 6 \\
\hline - Abnormal liver test & 12 \\
\hline - Pancreatic stricture & 3 \\
\hline - Other & 3 \\
\hline Prior stent placement (yes) & $44(51 \%)$ \\
\hline \multicolumn{2}{|l|}{ OCT location } \\
\hline - Biliary duct & 79 \\
\hline - Pancreatic duct & 7 \\
\hline \multicolumn{2}{|l|}{ OCT findings } \\
\hline - Dilated hypo-reflective Structures & 7 \\
\hline - Onion skin layering & 8 \\
\hline - Intact layering & 17 \\
\hline - Layering effacement & 25 \\
\hline - Scalloping & 20 \\
\hline - Thickened epithelium & 42 \\
\hline - Hyper-glandular & 13 \\
\hline - Prominent blood vessels & 6 \\
\hline - Hyper-reflective surface & 20 \\
\hline \multicolumn{2}{|l|}{ Final diagnosis } \\
\hline - Benign & $57(66 \%)$ \\
\hline - Malignant & $28(33 \%)$ \\
\hline - Dysplasia & 1 \\
\hline Adverse events $^{1}$ & $1 / 86(1 \%)$ \\
\hline Mean follow-up (months) & 4.65 \\
\hline \multicolumn{2}{|c|}{$\begin{array}{l}\text { ERCP, endoscopic retrograde cholangiopancreatography; OCT, optical co- } \\
\text { herence tomography } \\
1 \text { minor procedural bleeding treated with stent placement }\end{array}$} \\
\hline
\end{tabular}

Final diagnosis was malignant in 28 patients (33\%) and benign in 57 patients (66\%). Diagnosis was based on histology in 46 patients and pathology in 40 patients. One patient had minor bleeding during the RCP treated with biliary stent placement; no other adverse events were noted. Mean follow-up time was 4.7 months.

\section{Image analysis}

As described above, nine characteristics were analyzed ( $\triangleright$ Fig. 1 ): dilated hypo-reflective structures $(n=7)$, onion-skin layering $(n=8)$, intact layering $(n=17)$, layering effacement $(n=25)$, scalloping $(n=20)$, thickened epithelium $(n=42)$, hyper-glandular mucosa $(n=13)$, prominent blood vessels $(n=6)$, and a hyper-reflective surface $(n=20)$. After adjusting for all criteria, multivariate analysis using model selection (using one level for features, only predictors with $<0.10$ kept in model) showed that OCT findings of hyper-glandular mucosa had six times higher odds of being diagnosed as malignant $(P=0.0203 ; 95 \% \mathrm{Cl} 1.3$ to 26.5), a hyper-reflective surface had 4.7 times higher odds of being diagnosed as malignant ( $\mathrm{p} 0.025595 \% \mathrm{Cl} 1.2$ to 18.0 ) and scalloping had 7.9 times higher odds of being diagnosed as malignant ( $P=0.0035$; $95 \% \mathrm{Cl} 1.97$ to 31.8$)$.

\section{Discussion}

OCT evaluation of the pancreaticobiliary tree was first described by Tearney et al in 1998 [3] in which postmortem normal pancreaticobiliary tissue was analyzed and tissue microstructure was able to be successfully delineated. Additional exvivo studies ( $\triangleright$ Table 2 ) validated these initial findings both in the pancreatic duct $[7,8]$ and in the bile duct [9] and showed good correlation with histological comparison (respectively: sensitivity/specificity for discrimination between cancer and benign disease $78.6 \%$ and $88.9 \% ; 100 \%$ concordance with histology in malignancy, $80 \%$ in benign disease; and $100 \%$ concordance with histology in all cases). Subsequent in-vivo studies ( Table 3) confirmed the ability to delineate pancreaticobiliary architecture while also demonstrating feasibility and safety [4$6,10,11]$. Testoni et al [10] showed that OCT was superior to brush cytology in distinguishing non-neoplastic from neoplastic lesions in the pancreatic duct; Arvanitakis et al [11] found that two criteria for malignancy on OCT were identified in $53 \%$ of malignant strictures and one criteria in $79 \%$ patients and that OCT improved sensitivity and accuracy when compared to cytology brushing alone. Yet despite encouraging results, OCT technology was not adopted for widespread utilization likely due to shallow depth of penetration, suboptimal resolution, and technical difficulty in obtaining images.

The newer low-profile NVision VLE probe uses improved technology to increase resolution and increase depth of penetration. In addition, the catheter is flexible and more maneuverable through tortuous pancreaticobiliary anatomy without the need for an outer sheath, and the images are captured without the need for "pull-back technique" by the endoscopist. Such improvements may facilitate widespread adoption of this new technology. An ex-vivo study looking at 25 biliary and pancreatic samples confirmed the ability of the VLE probe to distinguish three histologic layers (epithelium, connective tissue, and parenchyma) [14]. In addition, distinctive patterns were noted for PSC and adenocarcinoma samples. Two small in-vivo studies by Tyberg et al and Joshi et al $(n=10, n=22$ respectively) also found characteristic features on image interpretation for malignant and benign strictures $[12,13]$. 


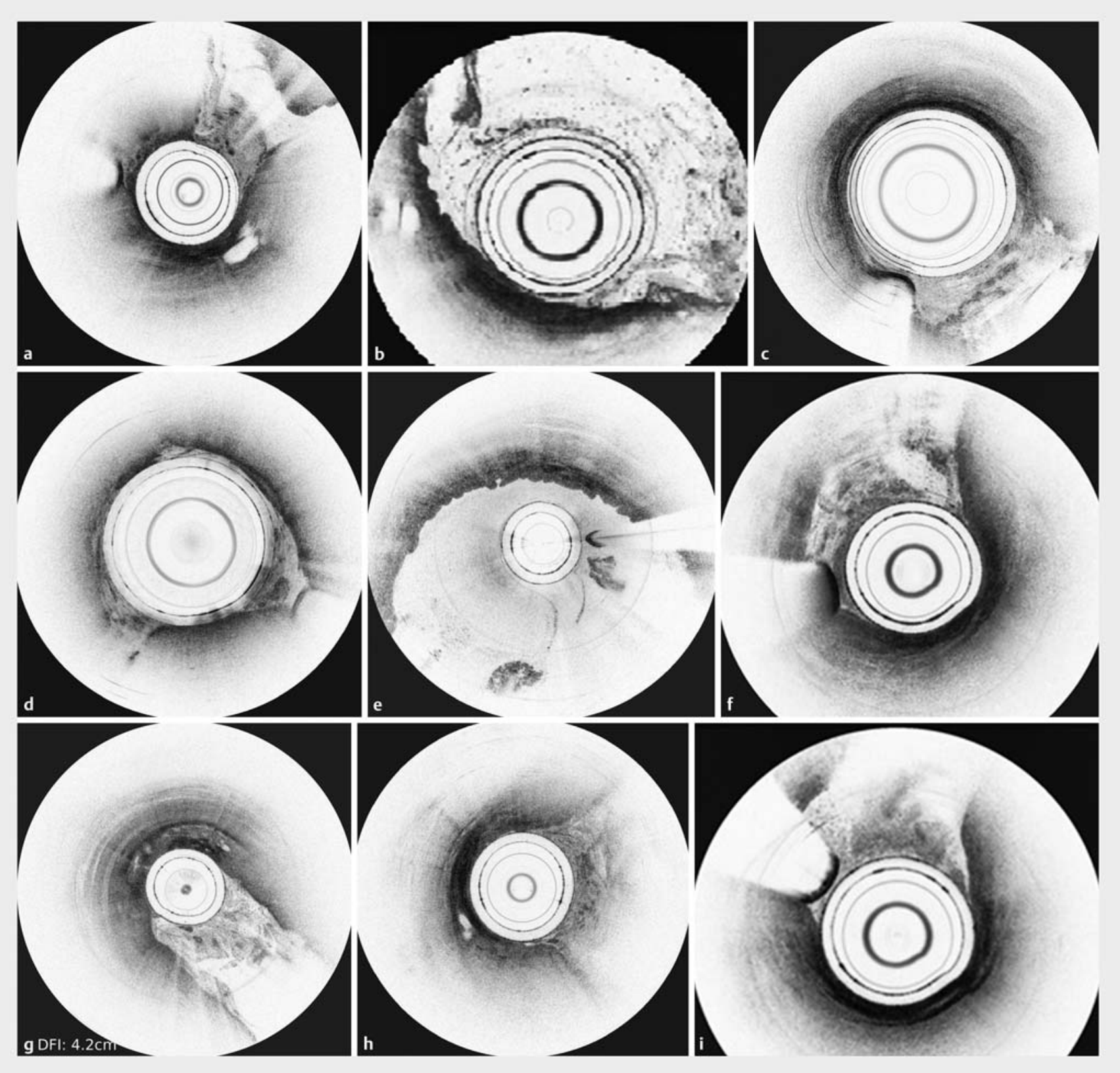

- Fig. 1 a Optical coherence imaging of dilated hyporeflective structure. b Optical coherence imaging of onion skin layering. c Optical coherence imaging of intact layering. $\mathbf{d}$ Optical coherence imaging of layering effacement. e Optical coherence imaging of scalloping. $\mathbf{f}$ Optical coherence imaging of thickened epithelium. $\mathbf{g}$ Optical coherence imaging of hyperglandular mucosa. $\mathbf{h}$ Optical coherence imaging of prominent blood vessels. i Optical coherence imaging of hyperreflective surface.

OCT offers several advantages over current diagnostic modalities for indeterminate strictures. Unlike cholangioscopy which allows for examination of the surface mucosa, OCT allows for under-the-surface evaluation, potentially capturing lesions that do not extend transmurally into the biliary or pancreatic ducts. OCT also allows for circumferential under-the-surface evaluation across $6 \mathrm{~cm}$ of tissue in 90 seconds, unlike confocal endomicroscopy which evaluates only small focal areas at one time. Additionally, the probe itself is smaller diameter than a cholangioscope and thus may more easily be advanced into narrow strictures. Yet despite the advantages, we predict that the optimal utility of OCT will be to be used in conjunction with other diagnostic modalities as opposed to on its own.

With any new technological modality, initial evaluation must ensure feasibility and safety. In prior studies, as well as in our data, the addition of performing OCT during ERCP does not seem to add risk to the procedure as evidenced by the low rate of adverse events [12]. Similarly, technical success was $100 \%$ indicative of widespread feasibility. The next step in evaluation is identifying characteristic criteria predictive of malignant or benign disease. In our study, the nine most frequent criteria were isolated and analyzed with several being significant pre- 
- Table2 Ex vivo studies of pancreaticobiliary OCT.

\begin{tabular}{|c|c|c|c|c|}
\hline Ex-vivo study & $\mathbf{N}$ & Location & Description & Findings \\
\hline Tearney et al 1998 & $\mathrm{n} / \mathrm{a}$ & $\begin{array}{l}\mathrm{GB}, \mathrm{BD}, \mathrm{PD} \text {, } \\
\text { pancreas }\end{array}$ & $\begin{array}{l}\text { Postmortem imaging of pancreatico- } \\
\text { biliary tissues compared to histology }\end{array}$ & $\begin{array}{l}\text { Tissue layers, glands, microvascula- } \\
\text { ture was delineated }\end{array}$ \\
\hline \multirow[t]{3}{*}{$\begin{array}{l}\text { Testoni et al } 2005 \text {, } \\
2006\end{array}$} & \multirow[t]{3}{*}{$\begin{array}{l}100 \text { images from } \\
10 \text { patients }\end{array}$} & \multirow[t]{3}{*}{ PD } & \multirow{3}{*}{$\begin{array}{l}\text { Ex-vivo imaging of malignant and be- } \\
\text { nign PD from patients with adenocar- } \\
\text { cinoma s/p whipple compared to cor- } \\
\text { responding histology }\end{array}$} & $\begin{array}{l}\text { Concordance of } 100 \% \text { in malignant } \\
\text { tissue, } 82 \% \text { in benign }\end{array}$ \\
\hline & & & & $\begin{array}{l}\text { Intra-observer reproducibility range } \\
85 \%-100 \%\end{array}$ \\
\hline & & & & $\begin{array}{l}\text { Unable to distinguish normal from } \\
\text { chronic pancreatitis }\end{array}$ \\
\hline \multirow[t]{2}{*}{ Testoni et al 2006} & \multirow[t]{2}{*}{$\begin{array}{l}60 \text { Images from } \\
5 \text { patients }\end{array}$} & \multirow[t]{2}{*}{$\mathrm{BD}, \mathrm{PD}, \mathrm{SOD}$} & \multirow{2}{*}{$\begin{array}{l}\text { Ex-vivo imaging of non-neoplastic } \\
\text { pancreatic specimens compared to } \\
\text { corresponding histology }\end{array}$} & $\begin{array}{l}\text { Three-layer wall architecture ob- } \\
\text { served in all cases }\end{array}$ \\
\hline & & & & $100 \%$ concordance with histology \\
\hline
\end{tabular}

OCT, optical coherence tomography; GB, gallbladder; BD, bile duct; PD, pancreatic duct; SOD, sphincter of Oddi

- Table 3 In vivo studies of pancreaticobiliary OCT

\begin{tabular}{|c|c|c|c|c|}
\hline In-vivo study & $\mathbf{N}$ & Location & Description & Findings \\
\hline \multirow[t]{2}{*}{ Seitz et al 2001} & \multirow[t]{2}{*}{4} & \multirow[t]{2}{*}{$\mathrm{BD}$} & \multirow[t]{2}{*}{ OCT images of BD during ERCP } & In-vivo OCT is feasible \\
\hline & & & & $\begin{array}{l}\text { Biliary tissue layers could be clearly } \\
\text { demonstrated }\end{array}$ \\
\hline Poneros et al 2002 & 5 & $\mathrm{BD}$ & $\begin{array}{l}\text { OCT images of BD during ERCP com- } \\
\text { pared with non-corresponding cada- } \\
\text { veric livers }\end{array}$ & $\begin{array}{l}\text { Biliary epithelium, glands, microvas- } \\
\text { cular visualized in-vivo }\end{array}$ \\
\hline \multirow[t]{2}{*}{ Singh et al 2005} & \multirow[t]{2}{*}{$\begin{array}{l}5 \text { dogs } \\
18 \text { images }\end{array}$} & \multirow[t]{2}{*}{$\mathrm{BD}, \mathrm{PD}$} & \multirow[t]{2}{*}{$\begin{array}{l}\text { OCT images of PD and BD compared } \\
\text { with histology after dogs euthanized }\end{array}$} & $\begin{array}{l}\text { Epithelial layer and peribiliary glands } \\
\text { were discernable }\end{array}$ \\
\hline & & & & $\begin{array}{l}\text { Nuclei and adjacent ductal structures } \\
\text { could not be identified }\end{array}$ \\
\hline \multirow[t]{4}{*}{ Testoni et al 2007} & \multirow[t]{4}{*}{$12^{1}$} & \multirow[t]{4}{*}{ PD } & \multirow{4}{*}{$\begin{array}{l}\text { OCT imaging of PD stricture during } \\
\text { ERCP } \\
2 \text { normal, } 3 \text { chronic panc, } 6 \text { malig- } \\
\text { nant }\end{array}$} & $\begin{array}{l}\text { Well-differential three-layer archi- } \\
\text { tecture in all cases of normal/chronic } \\
\text { pancreatitis }\end{array}$ \\
\hline & & & & $\begin{array}{l}\text { Subverted layering in malignant tis- } \\
\text { sue }\end{array}$ \\
\hline & & & & $\begin{array}{l}\text { Accuracy } 100 \% \text { for detection of ma- } \\
\text { lignancy }\end{array}$ \\
\hline & & & & $\begin{array}{l}\text { Unable to distinguish between be- } \\
\text { nign etiologies }\end{array}$ \\
\hline \multirow[t]{3}{*}{$\begin{array}{l}\text { Arvanitakis et al } \\
2008\end{array}$} & \multirow{3}{*}{$\begin{array}{l}37 \\
19 \text { malignant } \\
16 \text { benign }\end{array}$} & \multirow[t]{3}{*}{$\mathrm{BD}$} & \multirow[t]{3}{*}{$\begin{array}{l}\text { Malignancy criteria: layering efface- } \\
\text { ment + tumor vessels }\end{array}$} & $\begin{array}{l}2 \text { malignancy criteria in } 53 \% \text { malig- } \\
\text { nant and } 0 \% \text { benign }\end{array}$ \\
\hline & & & & $\begin{array}{l}1 \text { criterion in } 79 \% \text { malignant and } 31 \% \\
\text { benign }\end{array}$ \\
\hline & & & & $\begin{array}{l}\text { OCT added to cytology brushing im- } \\
\text { proved sensitivity and accuracy }\end{array}$ \\
\hline
\end{tabular}

dictors of malignant disease. This represents an exciting start for future study to further evaluate these criteria in a prospective, large-scale manner. Future studies will need to focus on determining inter-observer agreement amongst endoscopists in identifying established criteria. In addition, evaluating the sensitivity and specificy for OCT alone as well as in combination with other diagnostic modalities such as cholangioscopy and confocal endomicrosopy will need to be investigated. 
Limitations of the current study include the lack of comparison to histology in all patients as well as a limited follow-up time of only 4 months, though prior studies have confirmed that OCT findings correlate with corresponding histological specimens. In addition, several of the criteria had a small sample size limiting the ability to perform multi-variate analysis. Limitations of the technology include the lack of a wire-guided probe, potentially limiting usage in tight strictures. And lastly, a designation of malignant or benign was not determined based on OCT findings alone; instead, characteristics identified on OCT image interpretation were recorded. Thus, sensitivity and specificity as well as the diagnostic agreement compared to cholangioscopy and confocal endomicroscopy were not able to be performed in this study. However, this represents the first step in visually interpreting and confirming features using an exciting new technology and sets up future study questions including further evaluation of the identified criteria with large sample sizes, determining the influence of ERCP procedural factors on image interpretation such as prior stent placement, and the degree of inter-observer agreement that has limited adaptation of other imaging technology. These future study questions were addressed at a users' meeting during Digestive Disease Week 2018 in Washington, DC. Based on expert opinion and study results, the most promising criteria were selected, and the next study protocol was designed for further investigation.

\section{Conclusion}

In conclusion, newer generation OCT imaging presents an exciting new tool to improve sensitivity in diagnosing indeterminate biliary and pancreatic duct strictures by allowing for realtime, sub-surface evaluation of ductal microstructure that provides information not available via other currently available diagnostic techniques. Certain identifiable criteria seem to be predictive of malignant disease. However, further large-scale correlational studies are needed.

\section{Competing interests}

Dr. Raijman has served on the speaker/advisory board for Boston Scientific, advisory board for Pentax and Microtech, speakers boards for Conmed and Medtronic and is a co-owner of EndoRx. Dr. Sejpal is a consultant for Boston Scientific, Olympus and Ninepoint Medical and has received grant support from Boston Scientific. Dr. Das is a consultant for Boston Scientific, has received grant support from Interpace Diagnostics and Hygieacare Inc., and serves as a speaker for Olympus America. Dr. Sachdeve is a consultant and speaker for Boston Scientific, Olympus and Microtech and a speaker for Olympus and Aries. Drs. Tarnasky and Kedia are consultants for Boston Scientific. Dr. Gaidhane is a consultant for Interscope Med. Dr. Joshi is a consultant and receives research grants from Olympus America, Maunakea Technologies and Ninepoint Medical. Dr. Kahaleh receives grant support from Boston Scientific, MauneaKea, Apollo Endosurgery, Cook Endoscopy, ASPIRE Bariatrics, NinePoint Medical, Merit Medical, Olympus, and Interscope Med and is a consutlant for Boston Scientific, Concordia Laboratories, Inc., AbbVie and MaunaKea Tech.

\section{References}

[1] Slivka A, Gan I, Jamidar P et al. Validation of the diagnostic accuracy of probe-based confocal laser endomicroscopy for the characterization of indeterminate biliary strictures: results of a prospective multicenter international study. Gastrointest Endosc 2015; 81: 282-290

[2] Navaneethan U, Hasan MK, Kommaraju K et al. Digital, single-operator cholangiopancreatoscopy in the diagnosis and management of pancreatobiliary disorders: a multicenter clinical experience (with video). Gastrointest Endosc 2016; 84: 649-655

[3] Tearney G], Brezinski ME, Southern JF et al. Optical biopsy in human pancreatobiliary tissue using optical coherence tomography. Dig Dis Sci 1998; 43: 1193-1199

[4] Seitz U, Freund J, Jaeckle $S$ et al. First in vivo optical coherence tomography in the human bile duct. Endoscopy 2001; 33: 1018-1021

[5] Poneros JM, Tearney G], Shiskov M et al. Optical coherence tomography of the biliary tree during ERCP. Gastrointest Endosc 2002; 55: $84-88$

[6] Singh P, Chak A, Willis JE et al. In vivo optical coherence tomography imaging of the pancreatic and biliary ductal system. Gastrointest Endosc 2005; 62: 970-974

[7] Testoni PA, Mangiavillano B, Albarello L et al. Optical coherence tomography to detect epithelial lesions of the main pancreatic duct: an ex vivo study. Am J Gastroenterol 2005; 100: 2777-2783

[8] Testoni PA, Mangiavillano B, Albarello L et al. Optical coherence tomography compared with histology of the main pancreatic duct structure in normal and pathological conditions: an 'ex vivo study'. Dig Liver Dis 2006; 38: 688-695

[9] Testoni PA, Mariani A, Mangiavillano B et al. Main pancreatic duct, common bile duct and sphincter of Oddi structure visualized by optical coherence tomography: An ex vivo study compared with histology. Dig Liver Dis 2006; 38: 409-414

[10] Testoni PA, Mariani A, Mangiavillano B et al. Intraductal optical coherence tomography for investigating main pancreatic duct strictures. Am J Gastroenterol 2007; 102: 269-274

[11] Arvanitakis M, Hookey L, Tessier G et al. Intraductal optical coherence tomography during endoscopic retrograde cholangiopancreatography for investigation of biliary strictures. Endoscopy 2009; 41: 696701

[12] Tyberg A, Xu MM, Gaidhane M et al. Second generation optical coherence tomography: Preliminary experience in pancreatic and biliary strictures. Dig Liver Dis 2018; 50: 1214-1217

[13] Joshi V, Patel SN, Vandervelt H et al. Mo1963 A pilot study of safety and efficacy of directed cannulation with a low profile catheter (LP) and imaging characteristics of bile duct wall using optical coherance tomography (OCT) for indeterminate biliary strictures initial report on in-vivo evaluation during ERCP. Gastrointest Endosc 2017; 85: AB496-AB497

[14] Corral JE, Mousa OY, Krishna M et al. Volumetric laser endomicroscopy in the biliary and pancreatic ducts: a feasibility study with histological correlation. Endoscopy 2018; 50: 1089-1094

[15] Testoni PA, Mangiavillano B. Optical coherence tomography in detection of dysplasia and cancer of the gastrointestinal tract and biliopancreatic ductal system. World J Gastroenterol 2008; 14: 64446452 